\title{
Weber no Século XXI: Desafios e Dilemas de um Paradigma Weberiano
}

\section{Carlos Eduardo Sell}

Programa de Pós-Graduação em Sociologia Política da Universidade Federal de Santa Catarina (UFSC), Florianópolis, Santa Catarina, Brasil

$\mathrm{D}$ esde meados dos anos 1970, Heidelberg tem sido o palco de intenso trabalho de clarificação e atualização do pensamento weberiano. Em sua primeira fase, este esforço concentrou-se em um longo projeto de reinterpretação de sua obra. Denominado por alguns Weber-Renaissance, a hermenêutica do pensamento weberiano ocupou várias décadas de trabalho e significou uma espécie de reimportação da exegese weberiana da paisagem norte-americana para o campo acadêmico alemão. No pós-guerra, o eixo de gravidade de leitura e difusão da obra de Weber concentrou-se nos Estados Unidos, onde Talcott Parsons alçou Weber ao panteão sociológico ao lado de autores como Émile Durkheim, Vilfredo Pareto e Alfred Marshall. Nas décadas seguintes, a leitura normativista e evolucionista de Weber, proposta por Parsons, foi contestada por uma nova onda de pesquisadores alemães emigrados em terras norte-americanas. Liderada por nomes como Reinhard Bendix e Guenther Roth, a dimensão histórica e política do pensamento weberiano foi recuperada, resultando em um conflito aberto entre uma visão evolucionista e historicista de interpretação dos textos weberianos.

Um artigo seminal de Friedrich Tenbruck de 1975 transporta esta discussão para a Alemanha e propõe, contra a interpretação dominante (representada na Alemanha por Johannes Winckelmann), que não

DADOS - Revista de Ciências Sociais, Rio de Janeiro, vol. 57, no 1, 2014, pp. 35 a 71. 
"Economia e Sociedade", mas "A Ética Econômica das Religiões Mundiais" seria o eixo da teoria weberiana da modernidade, concebida como uma forma de evolucionismo idealista. Tal artigo gerou uma intensa discussão à qual reagiram estudiosos como Jürgen Habermas (1981) e, especialmente, Wolfgang Schluchter (1981). Este último, em particular, liderou um projeto que, durante décadas, produziu um novo padrão de leitura dos escritos de Weber. No centro desta leitura estava a tentativa de integrar a leitura evolucionista e historicista em um modelo denominado inicialmente desenvolvimental history (Entwicklungsgeschichte) e a tese de que seria o problema da determinação da gênese e das características do racionalismo ocidental e moderno o coração das investigações teóricas e empíricas de Max Weber. Embora a leitura proposta por Schluchter não seja aceita de forma unânime ${ }^{1}$, pode-se dizer que ela se tornou uma referência internacional de interpretação do pensamento de Weber.

Após este primeiro grande esforço de interpretação exegética e hermenêutica do pensamento weberiano, uma segunda geração de pesquisadores, de forma geral, também radicada em Heidelberg, vem procurando retomar esta leitura e direcioná-la no sentido da atualização da sociologia weberiana. Neste prisma, a pergunta que se coloca não é o problema hermenêutico de intelecção das intenções dos escritos weberianos, mas a pergunta teórica sobre a validade e a utilidade dos textos e ideias de Weber para a resolução dos problemas teóricos e empíricos presentes na agenda da sociologia contemporânea: não tanto o que Weber teria dito ou pensado, mas o que se pode fazer com seu pensamento nos dias de hoje, eis a pergunta central.

Os primeiros resultados desta busca são visíveis em um seminário realizado em Heidelberg, no ano de 2003. A coletânea que materializa os resultados deste encontro já mostra, em esboço, em que direções a pergunta acima procurou ser respondida. Conforme as contribuições dos expositores (Albert et al., 2003), a discussão concentrou-se nos fundamentos epistemológicos, na teoria da ação, nas instituições e ordens sociais e na dimensão da cultura e da conduta de vida. Esta primeira tentativa de atualização da sociologia de Max Weber também mostrou um desacordo sobre o caráter deste empreendimento, concebido por um determinado grupo como a tentativa de fixação de um "paradigma" (Lepsius, 2003:33-41 e Albert et al., 2006) ou, de outro lado, como a proposta mais modesta de um "programa de pesquisa" (Schluchter, 2005:42-76) de orientação weberiana. 
A divergência sobre as vias de atualização da teoria sociológica de Weber não se resume apenas a sua natureza epistemológica, mas estende-se também sobre o próprio conteúdo das questões e problemas a serem trabalhados e aprofundados. Desta feita, conforme a sistematização de Wolfgang Schluchter, um "programa de pesquisa de orientação weberiana" estaria assentado em dez premissas fundamentais: 1) racionalismo crítico; 2) tipos-ideais;3) compreensão explicativa; 4) racionalismo heurístico; 5) individualismo metodológico; 6) análise de múltiplos níveis;7) orientação por resultados ou valores intrínsecos; 8) discussão sobre valores; 9) conflitos de classe, de ordens de vida e de instituições e 10) personalidade. Gert Albert (2010), ao contrário, propõe explicitamente um "paradigma weberiano", embora explique que empregue o conceito de paradigma não no sentido de Thomas Kuhn, mas na acepção que lhe é dada por Robert Merton, qual seja, como um programa de pesquisa de médio alcance. Na visão deste último autor, a agenda a ser incluída no desenvolvimento deste paradigma inclui três grandes eixos que dizem respeito a problemas ontológicos, metodológicos e empíricos.

De novo, apesar da diferença terminológica empregada e, especialmente, do espectro de problemas a serem enfrentados, destaca-se o fato de que o projeto de recolocar o pensamento weberiano como uma proposta concorrente no quadro das teorias sociológicas atuais preserva o espírito não dogmático contido nas premissas da teoria de Max Weber. Isto significa que, em nenhum dos casos acima apontados, trata-se da tentativa do monopólio de fixação dos parâmetros epistemológicos, metodológicos ou substantivos da pesquisa sociológica, mas tão somente do esforço de alçar o pensamento weberiano a uma proposta concorrente no atual quadro multiparadigmático da ciência sociológica.

De um lado nota-se o esforço de desfossilizar a obra de Max Weber que, na condição de clássico, fica reduzido à condição de autor canônico e rotinizado na formação de cientistas sociais e fonte de citações ou empréstimos conceituais topicamente orientados em função de pesquisas específicas e localizadas, mas não uma fonte de problemas teóricos e empíricos que mobilizam a discussão científica. Por outro, este esforço de atualização, mais do que sistematizações teóricas amplas, tem se preocupado com o aprofundamento de áreas específicas da investigação social. Nesta direção, os pesquisadores de Heidelberg têm orientado as baterias weberianas na direção de discussões empíricas no cam- 
po da sociologia política (Lepsius, 1990), da teoria das organizações e instituições sociais (Stachura et al., 2009), da religião (Bienfait, 2011), da diferenciação social (Schwinn, Kroneberg e Greve, 2011), das desigualdades e configurações sociais (Sigmund e Albert, 2008) e até das formas contemporâneas de capitalismo (Pohlmann, 2006). Um amplo espectro de questões que mostra muita vitalidade e disposição de inovação.

Longe de perseguir direções tão distintas de trabalho, este texto procura sistematizar e discutir criticamente dois tópicos da agenda desenvolvida por seus proponentes, ambos situados nas pontas deste grande projeto teórico: 1) seus fundamentos teórico-metodológicos [Sozialtheorie] e 2) sua teoria da sociedade moderna [Gesellschaftstheorie]. Tenho consciência de que tal escolha restringe o horizonte da discussão a apenas dois itens, desconsiderando, inclusive, outros autores contemporâneos que também partem de Weber. De fato, importa lembrar que não se trata de sustentar que existe apenas um paradigma weberiano, e que diversos desdobramentos de sua obra são possíveis e igualmente válidos ${ }^{2}$. Da mesma forma, cabe justificar que, embora me concentre apenas nestas duas questões, julgo que elas são estratégicas para caracterizar as discussões que, buscando atualizar Weber, desenrolam-se, hoje, na Alemanha. Se elas não recobrem todo o amplíssimo espectro de questões da discussão sobre a obra do autor, fornecem, contudo, um panorama significativo do que poderia ser elevar seu pensamento a posto de "paradigma sociológico" contemporâneo, abrindo espaço para delinear algumas das contribuições, mas também dos problemas que tal tentativa engendra.

A partir deste recorte, o primeiro desses tópicos concentra-se em determinar a posição do paradigma weberiano em relação ao problema contemporâneo das relações entre "micro e macro" na teoria social, e o segundo debruça-se sobre a tentativa dos teóricos neoweberianos em oferecer uma alternativa ao debate sobre o caráter da modernidade em tempos atuais. Ambos os tópicos serão esboçados e desembocam em uma avaliação preliminar das contribuições, limites e impasses que tal proposta tem enfrentado.

\section{WEBER NO DEBATE INDIVIDUALISMO VERSUS HOLISMO: PRIMEIRA, SEGUNDA OU TERCEIRA VIA?}

Conforme Jeffrey Alexander (1987), desde meados dos anos 1980 a sociologia caminha na direção de um "novo movimento teórico". No seu 
entender, após o predomínio das concepções macrossociológicas e das reações contrárias, de tipo microssociológico, são as tentativas de integração de ambas as abordagens que predominam. Tentando reconciliar individualismo metodológico, de um lado, e holismo metodológico, de outro, nomes como Pierre Bourdieu, Anthony Giddens, Margareth Archer ou mesmo Jürgen Habermas seriam algumas das referências na busca de integrar "agente" e "estrutura" em um modelo teórico sintético que contemple o papel das duas variáveis em questão ${ }^{3}$.

Neste debate já é mais do que usual a apresentação de Weber como o protótipo por excelência da concepção individualista. Partindo de suas próprias declarações, o indivíduo seria o átomo de seu método sociológico. Tal declaração, contudo, não nos deve conduzir tão rapidamente à tese de que Weber seria o nobre ancestral do qual derivam todas as vertentes do individualismo metodológico. Mesmo que ele tenha se declarado abertamente contra uma visão organicista de sociologia, não era nos termos "individualismo" $x$ "holismo" que o debate metodológico de seu tempo se efetuava e não é exatamente a este problema que sua obra responde. Tal enquadramento é fruto da própria institucionalização da sociologia como ciência e de seus debates internos. Por isso, nem todos os comentadores são concordes em adjudicar a Weber o posto de patrono da primeira posição, advindo daí posições mais matizadas, como aquelas que podemos encontrar em Guenther Roth (1968) ou Gabriel Cohn (2003), por exemplo. Ambos evitam o rótulo por demais fácil de "individualista metodológico". Tais autores nos convidam a ir além das apresentações históricas e de caracterizações didáticas, nas quais Weber ocupa o reduzido posto de precursor. Indo além do papel histórico e modelar, a pergunta que se coloca é: qual o lugar e qual a contribuição efetiva que o pensamento de Max Weber pode oferecer para o atual debate micro-macro na Sociologia? Para responder a esta pergunta, vou servir-me de dois autores do "neoweberianismo" situando a contribuição do primeiro (Schluchter) no plano micro e a contribuição do segundo (Albert) no plano das relações entre a escala micro e a escala macrossocial.

Nossa reflexão começa, pois, tomando como ponto de partida o fundamento incontornável da sociologia weberiana: sua teoria da "agência" social, qual seja, vamos partir do plano micro. A mais do que célebre tipologia das formas de ação, apresentada por Weber em Economia e Sociedade, por suposto conhecida, não necessita aqui ser recapitulada. De fato, mais complexa se torna a exposição se perguntarmos sobre qual a 
natureza epistemológica da concepção de ação que preside a explanação weberiana, tema ao qual Wolfgang Schluchter busca dar uma resposta exegeticamente fundamentada e teoricamente plausível. Após uma primeira tentativa de sistematização da teoria weberiana da ação, em que se propunha a ordená-la a partir de quatro elementos (fins, valores meios e efeitos), presentes em uma escala decrescente em cada um dos tipos de ação, o perito apresentou nova proposta, em 19964. Em termos sistemáticos, Schluchter (2000) preocupou-se em situar a sociologia weberiana no quadro das disputas do meio sociológico alemão, no qual a teoria dos sistemas de Niklas Luhmann (holismo metodológico), a teoria da escolha racional e a teoria da ação comunicativa de Jürgen Habermas (individualismo metodológico) ocupavam a cena teórica. Situando a sociologia de Weber neste segundo lado, ele procurou defendê-la do reducionismo economicista que lhe era atribuído positivamente pela teoria da escolha racional ou negativamente pela teoria da ação comunicativa. O que Schluchter contestava, acima de tudo, era a prioridade analítica (quando não exclusividade) que ambas as abordagens atribuíam ao tipo "ação racional com relação a fins" no esquema weberiano (primado do homo economicus). Ao mesmo tempo, ele procurou mostrar em que medida o individualismo metodológico de Weber era imune à crítica da "filosofia da intersubjetividade" de Habermas.

Na sua elaboração teórica, Schluchter (2009) utiliza-se, enquanto instrumento auxiliar, do esquema desenvolvido por Hartmut Esser (1993), autor que, apesar de se situar claramente no plano da teoria da escolha racional, não professa qualquer forma de atomismo social que negue substancialidade ao nível das instituições sociais. Segundo Esser, a tarefa fundamental da sociologia é explicar fenômenos de nível macro, embora seu ponto de partida sejam sempre seus microfundamentos. A partir desse pressuposto, a análise social precisa distinguir três momentos diferentes. O primeiro refere-se à lógica da situação e diz respeito às influências das estruturas sobre o nível da ação (macro-micro). O segundo momento - situado por inteiro no plano micro refere-se à lógica da seleção e envolve as linhas de ação escolhidas pelo ator (micro-micro). O terceiro nível é denominado lógica da agregação e diz respeito aos influxos da escala micro sobre a escala estrutural (micro-macro). Este esquema é particularmente útil para Schluchter porque lhe permite diferenciar em Weber um plano micro e um plano macro claramente demarcados: a sociologia weberiana seria, sob este prisma, um modelo teórico de múltiplos níveis [Mehr-Ebenen-Modells]. 
Nesta direção, o plano micro envolve os mecanismos de orientação da ação e diz respeito à tipologia weberiana das ações sociais. Já o plano macro envolve a transição para os mecanismos de coordenação da ação, incluindo tanto as relações sociais quanto sua configuração em ordens sociais motivadas por interesses (como o mercado) ou segundo princípios normativos (como a esfera política e jurídica), incluindo ainda a institucionalização destas relações em organizações formais (administrativas ou políticas). Finalmente, em um terceiro nível, ainda mais amplo, Weber apresenta uma teoria da cultura que se refere à forma como modos de orientação da ação e estrutura sociais estão institucionalizados em civilizações historicamente determinadas. Vejamos como Schluchter interpreta a obra de Weber no que diz respeito ao plano microssociológico.

O ponto de partida da sociologia individualista de Weber é a diferenciação entre "comportamento" (Verhalten) e "ação" (Handeln), o que significa que o elemento que define a ação é um sentido subjetivamente visado, ou ainda, a diferença entre comportamento motivado ou não (somente este último é passível de compreensão). A partir deste fundamento, Weber constrói uma tipologia dos mecanismos de orientação da ação que obedece a uma escala que passa das ações irracionais para as racionais (perspectiva ascendente). No ponto de partida estão as ações habituais rotinizadas que envolvem o mínimo de consciência dos planos de ação, pois estes estão subconscientemente incorporados. De outro lado estão as ações afetivas que obedecem a reações espontâneas e, neste sentido, são inconscientes. Para Schluchter, interpretando Weber, os dois casos se referem a formas de ação que não são passíveis de racionalização. No plano posterior das formas de ação racionais encontram-se, em igual nível, aquelas que são reguladas por máximas práticas (ação racional com relação a fins) que se orientam pelo sucesso ou por máximas imperativas (em que o fundamento da ação é uma afirmação de princípio) nas quais a representação da validade em si é o móvel da ação. Conforme a concisa descrição de Schluchter (2009:129):

Nós podemos ordenar as formas de orientação da ação segundo uma ordem lógica conforme elas são passíveis de classificação segundo as possibilidades dos fins visados. Conforme esta sequência podemos dizer: uma ação obedece a um hábito ou não? Se não obedece a um hábito, ela pode ser espontânea ou orientada por regras e, quando orientada por regras, pode ser orientada por máximas finais ou máximas normativas. 
Fundamental é observar que, na visão deste autor, rejeita-se claramente a tese convencional segundo a qual a ação com relação a fins tem prioridade analítica no esquema sociológico weberiano. Schluchter é enfático e insiste na tese de que o método de Weber é teleológico apenas em sentido amplo, pois ele combina três elementos: fins (Zweck), meios (Mittel) e, não menos importante, valores (Wert).

Com base nos pressupostos acima, a reconstrução exegética efetuada por Schluchter posiciona-se diante das abordagens concorrentes, seja em relação à teoria da escolha racional que, na prática, restringe-se ao primeiro dos tipos de ação; ou mesmo em relação à teoria da ação comunicativa que dualiza normativamente e hierarquicamente entre uma forma de ação teleológica (atribuída a Weber) e outra forma comunicativa. Para Schluchter, a teoria weberiana da ação social, na medida em que equilibra o plano "utilitário" e o plano "valorativo", integra e abrange tanto o modelo de ação orientado por normas (Talcott Parsons) quanto a ação estratégica (teoria da escolha racional) sem dualizá-las, remetendo uma ao campo dos sistemas e outra ao campo do mundo da vida. Schluchter observa ainda que o modelo de ação adotado por Weber não é intersubjetivo como aquele proposto por Habermas, e se aproxima do modelo praxiológico que podemos encontrar em Pierre Bourdieu. Não obstante, em termos weberianos, a proposta bourdiesiana prioriza o nível das práticas sociais rotinizadas (ação tradicional/habitus), em claro contraste com o pensamento weberiano que enfatiza a racionalização crescente dos níveis de ação ${ }^{5}$.

As últimas alusões e confrontações feitas acima (que, obviamente, ainda merecem ser melhor exploradas) mostram que a interpretação exegética realizada por Schluchter também está acoplada à intenção de fornecer um marco analítico que mostra a atualidade da teoria weberiana da ação. No entanto, este debate possui outro problema central, e ele vai além da mera determinação da natureza da "teoria weberiana da agência social" isoladamente considerada: trata-se do problema da articulação entre o plano microfundante da ação social e sua tradução para o plano emergente da ordem ou das macroestruturas sociais.

Para tratar deste tema, apresento as conclusões de um dos membros mais jovens do círculo weberiano (Gert Albert), cuja preocupação também é desviar-se de outro rótulo convencional atribuído a Weber: o individualismo metodológico. Clássico e pai da teoria da ação social, 
mas não exatamente um individualista metodológico. Do que se trata? Já para Thomas Schwinn (1993b), além de distinguir claramente o plano micro do plano mais amplo das macroestruturas, não haveria qualquer primado de nenhuma das esferas na sociologia weberiana. Albert (2005) persegue esta pista e insiste na mesma tendência antirreducionista presente em Weber. Para chegar a este resultado ele aprimora a usual divisão entre o individualismo e o holismo distinguindo, em cada uma delas, uma tendência radical e outra moderada. A diferenciação entre estas diferentes tendências é feita a partir de três critérios. O primeiro deles é a concepção de emergência que pode ser de tipo "fraco" ou "forte". A pergunta aqui é se o nível emergente (no caso, as estruturas sociais) possui substancialidade própria e independente (irredutibilidade), ou, ao contrário, requer necessariamente a redução ao nível individual. O segundo critério pergunta-se pela direção da relação entre os dois níveis e é chamado de causalidade. Distingue-se uma vertente que apregoa apenas determinações do nível macro sobre o nível micro ou, ao contrário, admite também a possibilidade da causação do plano da ação para o plano da estrutura: a questão aqui é de onde parte o fator causal. O terceiro elemento que compõe o modelo de Albert é chamado de explicação. Neste caso, a pergunta a ser feita é se estamos apenas diante de problemas de definição passíveis de clarificação analítica ou se, de fato, trata-se de uma explicação causal que pode ser, novamente, de tipo "forte" ou "fraco": o problema central é o tipo (ou qual a natureza) de relação causal entre o plano micro e o plano macro. Se a redução da estrutura à ação é necessária, então a explicação é considerada de tipo "forte". Mas, se o nível macro da ordem social tiver propriedades intrínsecas, ele não requer necessariamente a redução ao plano dos atores, ou seja, a relação (no nível explicativo) entre os dois níveis é de tipo "fraco". Retomando e combinando estes três elementos, Albert identifica quatro modelos de teoria sociológica.

O primeiro destes modelos é o individualismo metodológico moderado (micro-micro-macro). Ele admite a possibilidade de que o nível estrutural possua características próprias, mas elas são de tipo "fraco". Isto significa que alterações nas propriedades do Sistema "S" são possíveis apenas porque foram verificadas alterações no nível elementar " $Y$ ". A causalidade, portanto, vai apenas na direção do nível micro para o nível macro, não havendo possibilidade de causação contrária: por isso, trata-se de explicações de tipo "forte" (que requer sempre o movimento de redução ao plano dos atores). Como exemplo deste tipo de posição Gert Albert menciona a obra de Hartmut Esser (1993) que, a despei- 
to de defender claramente as premissas da escolha racional, não advoga um atomismo extremo que negue a existência de fato de estruturas coletivas.

Na concepção do individualismo metodológico radical (micro-micro), ao contrário, fenômenos de nível macro não possuem qualquer propriedade emergente e as possibilidades de causação do nível micro para o nível macro são simplesmente inexistentes. Nesta visão, fenômenos de tipo coletivo são apenas arranjos e combinações contingentes de elementos individuais e toda alteração no conjunto nada mais é que o resultado da alteração de seus microcomponentes. A causalidade ocorre apenas no nível dos atores mesmos, em termos de suas relações mútuas, e a relação causal entre o nível macro e o nível micro é apenas uma questão de esclarecimento analítico-conceitual (não há, propriamente falando, elementos explicativos).

No campo das teorias adversárias, o holismo metodológico radical (macro-macro), consubstanciado em nomes como Peter Blau e o neoinstitucionalismo, simplesmente exclui o plano micro do horizonte da análise, operando uma disjunção completa entre o plano macro e o plano micro. O plano macroestrutural possui um conjunto de propriedades intrínsecas de tipo forte (plano da emergência) cuja causação atua sobre outras estruturas (causalidade de tipo forte) e cuja determinação teórica é do tipo sintético.

Finalmente, o holismo metodológico moderado (macro-micro-macro), posição na qual o intérprete situa Max Weber, caracteriza-se por manter a distinção entre o plano macro e o plano micro. Esta tendência atribui propriedades emergentes ao plano macro, mas estas podem ser tanto fracas quanto fortes. Em termos de causação, este modelo aponta para os reflexos do plano da ação sobre o plano da estrutura, ao mesmo tempo que não nega a possibilidade dos reflexos do plano da estrutura sobre o plano da ação. A relação entre o nível macro e o nível micro não é de tipo forte, pois nem sempre a redução ao plano da ação é necessária para a análise. Esquematicamente, a tipologia de Albert pode ser apreciada no Quadro 1.

O que justifica o fato de que, contrariando a compreensão padrão, Albert situe Max Weber não em uma versão radical ou moderada do Individualismo, mas justamente na versão mais moderada do Holismo? Neste caso, em vez de fixar-se apenas nos escritos metodológicos weberianos, o intérprete foi buscar inspiração nas análises histórico- 
Weber no Século XXI: Desafios e Dilemas de um Paradigma Weberiano

Quadro 1

Critérios de Distinção de Quatro Posições Metodológicas

\begin{tabular}{|l|l|l|l|l|}
\hline & $\begin{array}{l}\text { Holismo } \\
\text { Radical }\end{array}$ & $\begin{array}{l}\text { Individualismo } \\
\text { Radical }\end{array}$ & $\begin{array}{l}\text { Individualismo } \\
\text { Moderado }\end{array}$ & $\begin{array}{l}\text { Holismo } \\
\text { Moderado }\end{array}$ \\
\hline Emergência & Forte & Inexistente & Fraco & Fraco e forte \\
\hline Causalidade & $\begin{array}{l}\text { Same-level } \\
\text { causation } \\
\text { (macro) }\end{array}$ & $\begin{array}{l}\text { Same-level causa- } \\
\text { tion } \\
\text { (micro) }\end{array}$ & $\begin{array}{l}\text { Apenas upward } \\
\text { causation (ma- } \\
\text { cro-micro-ma- } \\
\text { cro) }\end{array}$ & $\begin{array}{l}\text { Também down- } \\
\text { ward } \\
\text { causation (ma- } \\
\text { cro-micro-ma- } \\
\text { cro) }\end{array}$ \\
\hline $\begin{array}{l}\text { Relação } \\
\text { Micro-Macro }\end{array}$ & $\begin{array}{l}\text { Fusão do micro } \\
\text { no plano macro }\end{array}$ & $\begin{array}{l}\text { Proposições } \\
\text { analíticas }\end{array}$ & $\begin{array}{l}\text { Explicações for- } \\
\text { tes }\end{array}$ & $\begin{array}{l}\text { Explicações fra- } \\
\text { cas }\end{array}$ \\
\hline $\begin{array}{l}\text { Modelo Expli- } \\
\text { cativo }\end{array}$ & $\begin{array}{l}\text { Macro-macro } \\
\text { "Macro"-micro- } \\
\text { "macro" }\end{array}$ & $\begin{array}{l}\text { Macro-mi- } \\
\text { cro-macro }\end{array}$ & $\begin{array}{l}\text { Macro-mi- } \\
\text { cro-macro }\end{array}$ \\
\hline
\end{tabular}

Fonte: Albert (2005:389).

empíricas do pensador, a começar por A Ética Protestante e o "Espírito" do Capitalismo. Seguindo aqui uma sugestão aventada primeiramente por David McCLellan (1961) e depois aprofundada por James Coleman (1990), ele mostra como o estudo de Weber implica a clara distinção entre dois níveis da análise sociológica. No centro da análise weberiana encontra-se uma relação causal entre duas variáveis situadas no plano macro: a religião (protestantismo ascético) e a economia (capitalismo moderno). Consoante o modelo weberiano não estamos diante da causação direta entre as duas variáveis, pois o influxo do primeiro sobre o segundo é mediado, necessariamente, pelo plano micro. Nestes termos, um conjunto determinado de crenças objetivadas no sistema religioso (lógica da situação ou plano macro-micro) orienta o sistema de referência dos indivíduos. Esta lógica religiosa, por sua vez, desencadeia motivações na esfera do comportamento econômico (lógica da ação ou plano micro-micro), qual seja, engendrando uma forma determinada de "espírito capitalista" de feições éticas. Esta forma de ação, por sua vez, está em uma relação e adequação com uma determinada estrutura econômica (lógica da agregação ou plano micro-macro). Mais interessante ainda é a análise que Albert nos oferece da tipologia das formas de dominação de Max Weber. Seguindo uma discussão já recorrente nos estudos sobre o pensamento político weberiano, Albert destaca que os tipos de dominação são, antes de tudo, fenômenos da ordem ou das instituições e, como tais, possuem propriedades emergentes, ainda que eles não possam ser desvinculados de um determinado sistema de crenças dos indivíduos (legitimidade). Mais uma vez, 
o que existe entre estes dois planos é uma relação de circularidade que leva tanto do plano micro ao macro como na sua direção contrária.

A inusitada posição de Albert em relação a Max Weber não demorou a encontrar críticas. Segundo Jens Greve (2006), pressupor que a sociologia weberiana possui uma concepção fraca do papel causal dos níveis estruturais implicaria inevitável contradição, pois, neste caso, as estruturas não repercutem causalmente sobre os indivíduos: não se pode sustentar que a realidade social constitui-se primariamente de indivíduos e ao mesmo tempo afirmar que estruturas transindividuais exercem ação sobre eles. Sendo assim, após uma rodada de discussões Albert modifica sua posição, abandonando a tentativa de situar a sociologia weberiana no campo do holismo em sua versão branda. Mas, em vez de devolvê-la ao campo já tradicional do individualismo metodológico, Albert (2009 e 2011) simplesmente transcende a divisão e passa a advogar que a posição metodológica weberiana pode ser situada como uma terceira via que evita tanto a tendência reducionista de privilegiar o polo da ação sobre o polo da estrutura (atomismo) ou, ao contrário, o polo da estrutura sobre o plano do agente (coletivismo) ${ }^{6}$. Na senda de autores como Pierre Bourdieu, Habermas ou, para empregar aqui a já usual expressão de Anthony Giddens, Weber seria, avant la lettre, um teórico da "dualidade da estrutura". Nem só as estruturas (primeira via), nem somente a agência (segunda via), o fato é que Weber nos abre um caminho para uma terceira via que integra as duas abordagens concorrentes.

\section{DA ORIGEM À EXPANSÃO E DIVERSIFICAÇÃO DO MODERNO: AS MÚLTI- PLAS FORMAS DE MODERNIDADE ENTRE CULTURA E ESTRUTURA}

Antes de entrar no mérito das questões que ambas as posições levantam, passemos do plano abstrato da teoria sociológica e do problema micro/macro ao plano histórico-empírico, mas não menos vasto, da teoria da modernidade. Aqui um programa de pesquisa orientado em Max Weber enfrenta um desafio diferente daquele posto no âmbito teórico. Não se trata de atualizar ou mesmo corrigir o já desenvolvido na teoria weberiana (supondo sua validade), mas enfrentar uma realidade diversa daquela pesquisada por ele. Se no centro da teoria weberiana estava a problemática da gênese e da caracterização do mundo moderno, o desafio agora é pensar os desenvolvimentos e transformações, bem como a expansão e diversificação da experiência moderna (Schwinn, 2004), qual seja, temas que não estão explicitamente con- 
templados por Weber. Para responder a este desafio, o caminho escolhido foi a adoção de uma ideia (para não falar em conceito) que, mesmo nascida sob a inspiração de Weber, lhe é incorporada de fora: a ideia de modernidades múltiplas, desenvolvida por Shmuel Eisenstadt. A que resultados esta estratégia conduziu até agora e qual sua potencialidade, contribuições e limites? Tal como já fiz na seção anterior dedico este tópico a descrever as linhas desta orientação, servindo-me do trabalho de dois autores, ambos de diferentes gerações. Primeiro apresento a teoria das modernidades múltiplas do próprio Eisenstadt para, depois, descrever os padrões de seu desenvolvimento por parte de Thomas Schwinn.

No Brasil, a penetração das teorias da globalização, das abordagens pós-coloniais e, recentemente, das modernidades globais (Domingues, 2013), tem sido muito rápida e mesmo a ideia das modernidades múltiplas já se acha, há algum tempo, presente na discussão acadêmi$\mathrm{ca}^{7}$. Não obstante, creio que ainda carecemos de exposições mais amplas e sistemáticas da proposta de Shmuel Eisenstadt e mesmo uma avaliação mais detalhada de seus possíveis méritos e limites. De modo geral, os críticos de sua proposta têm alegado que seu trabalho é tributário das teorias da modernização (Joas e Knöbl, 2004). Rejeitando esta interpretação, pretendo mostrar que a obra de Eisenstadt comporta uma evolução na qual estas premissas são lentamente abandonadas e reformuladas (Preyer, 2011). Meu propósito será demarcar qual o lugar e o papel da obra de Weber ao longo deste desenvolvimento ${ }^{8}$.

O polônes Shmuel Noah Eisenstadt (1923-2010), que fora da Universidade Hebraica de Israel, iniciou sua formação sob a orientação de Martin Buber, tendo realizado estágios de formação em Londres (1947-48) e nos Estados Unidos (entre 1956-57). Além de estudos sobre migração, a primeira fase da obra deste autor é marcada pelo projeto de uma vasta sociologia comparativa, cujo foco era a transição das sociedades tribais para os grandes impérios do mundo antigo. Os resultados desta pesquisa foram publicados no ano de 1963, em The Political Systems of Empires. Nesta primeira grande fase, a orientação teórica decisiva da pesquisa de Eisenstadt é dada pela combinação entre elementos do estrutural-funcionalismo parsoniano e da sociologia política de Weber. Procurando superar o esquema sincrônico da teoria dos sistemas sociais, ele busca mostrar como a disputa pela monopolização dos recursos em sistemas sociais complexos (Civilizações), controlados por vastas burocracias (Impérios), comporta a necessidade de mecanismos de 
legitimação política. Ou seja, em vez de relações funcionais entre subsistemas, a integração social comporta uma disputa estrutural de diferentes elites por recursos. Apesar dos elementos críticos, com ênfase em fatores dinâmicos e conflitivos que Eisenstadt injeta no esquema sistêmico, sua proposta não se distancia do modelo das teorias da modernização vigente nos anos 1960 e 1970, cuja premissa básica era a convergência dos processos de transição das sociedades tradicionais para as modernas.

Segue-se, então, uma fase intermediária (Eisenstadt, 1966 e 1978), momento em que além de pesquisas sobre o tema dos protestos e das revoluções (e cuja tentativa de aproximação crítica com a nova sociologia histórica, então em plena efervescência, é claramente visível), novas premissas teóricas são desenvolvidas. Também neste momento, a obra de Max Weber continua a desempenhar papel importante. Em colaboração com Edward Shils, Eisenstadt (1968) aproxima-se da tese da rotinização do carisma e amplia esta noção do seu âmbito político para o plano mais amplo das estruturas sociais. Nesta leitura (que lembra o núcleo "sagrado" do social de Durkheim), os sistemas sociais são arranjos estruturais contingentes e dinâmicos que institucionalizam elementos carismáticos localizados em seu interior: a ordem social é sempre dinâmica e envolve o confronto e disputa constante entre centro e periferia.

Até este momento, a obra de Eisenstadt pode ser compreendida como uma versão weberianizante do funcionalismo (como a definiram Alexander e Colomy, 1985). Mas este não é o caso para suas obras posteriores, como os próprios partidários do funcionalismo reconheceram (Alexander, 1992). A transição de uma sociologia política (comparativa) dos sistemas burocráticos na direção de uma sociologia cultural (comparativa) das civilizações já pode ser identificada nos anos 1980, não sem a decisiva estadia de Eisenstadt em Heidelberg onde, em 1987, colaborando com Wolfgang Schluchter, atuou na qualidade de professor visitante, parceria que continuou ainda nos anos seguintes na qualidade de professor visitante no Max-Weber-Kolleg da Universidade de Erfurt. Desta feita, colocando a sociologia weberiana da religião no centro de sua teorização, Eisenstadt desenvolveu as premissas fundamentais de sua abordagem das modernidades múltiplas. Metodologicamente, ele adota o esquema sociológico weberiano tal como elaborado por Schluchter, no qual são divisados três níveis diferentes de análise: o nível da ação, o nível das instituições (ordem social) e o nível da 
cultura (civilizações). A partir destas balizas gerais, ele distingue entre dois momentos diversos da história social: a primeira era axial e a segunda era axial (Eisenstadt, 1982 e 1986).

O conceito de "era axial", retirado da obra de Karl Jaspers (1949), já havia sido utilizado também pelo irmão de Max Weber, Alfred Weber (1997), em sua proposta de uma sociologia histórico-cultural. Ao adotar esta noção, Eisenstadt se move da combinação entre o funcionalismo modernizante (Parsons) e abordagem carismático-política (Weber) para uma perspectiva culturalista na qual o comparativismo weberiano das grandes religiões universais passa a ocupar, agora, o posto central. Eisenstadt entende seu trabalho como uma continuidade da obra de Max Weber, pois a ideia de uma primeira era axial retoma, em nova nomenclatura, os estudos sobre as religiões mundiais da fase madura deste pensador. Comparando as religiões orientais de afirmação do mundo da China (Confucionismo e Taoísmo) e de negação do mundo da Índia (Hinduísmo e Budismo), Weber procurou identificar a especificidade do racionalismo ocidental. Traçando suas raízes no profetismo judaico até chegar ao protestantismo ascético, ele viu na história do ocidente uma linha evolutiva que, através de um processo de desencantamento do mundo (Pierucci, 2003), desembocava em uma forma ético-prática de racionalismo.

Retomando as premissas gerais da formulação weberiana, Eisenstadt apresenta sua própria concepção da primeira era axial. Assim, ainda que a ênfase no comparativismo weberiano comporte um eurocentrismo heurístico (dado que o esforço comparativo volta-se para outras civilizações apenas como recurso metodológico de contraste), que o leva a apontar o que é "específico" em cada civilização (adaptação ao mundo/China, fuga do mundo/Índia, aceitação do mundo/Judaísmo Antigo e dominação do mundo/Protestantismo Ascético), o sociólogo busca identificar em todo este conjunto um elemento axiológico comum: daí ele poder falar em "primeira era axial". Trata-se da ideia de transcendência. O processo de evolução das crenças na direção da superação do universo mágico-cosmológico e o surgimento de religiões de salvação comportam uma tensão entre a ordem social mundana e a ordem simbólico-normativa do religioso (dimensão cultural). Esta questão ontológica básica engendra um problema que recebe respostas diversificadas, originando visões de mundo que são elaboradas a depender do resultado da disputa entre elites intelectuais (dimensão dos atores) de orientação ortodoxa e heterodoxa que podem estar a ser- 
viço ou em oposição ao poder político (dimensão estrutural). Sob esse prisma ele vê nas civilizações orientais religiões baseadas em uma imagem impessoal do divino, que desembocam ou na sacralização da ordem social (China) ou em uma orientação supramundana (Índia), enquanto no Ocidente a concepção pessoal do divino desagua em civilizações monoteístas (Judaísmo, Cristianismo e Islamismo) que combinam, de forma tensa e complexa, elementos extramundanos ou intramundanos.

Outro elemento no qual Eisenstadt retoma e ao mesmo tempo busca superar Weber é a distinção de uma segunda era axial que, na visão do intérprete, este teria descrito de forma unilateral. Ou seja, enquanto Weber apresentou uma teoria da gênese da modernidade assumindo como premissa a existência de uma única versão ocidental-europeia, Eisenstadt se propõe a mostrar que a institucionalização da ordem social moderna é, desde o seu início, um processo multifacetado. Neste caso, trata-se de mostrar que, alcançado um determinado estágio evolutivo, múltiplas alternativas de desenvolvimento são abertas. O estágio aponta para o princípio da unidade e as alternativas para o princípio da diversidade, sendo que nenhuma das alternativas engloba por inteiro as possibilidades que são abertas. Na crítica de Eisenstadt, embora Weber tenha seguido este modelo em sua análise da primeira era axial (Ocidente), o mesmo não se aplica à sua análise da segunda era axial (Modernidade), pois ele só descreveu uma única alternativa histórica. É neste contexto que se insere a ideia da "variedade" de civilizações modernas. Examinemos este ponto com mais vagar.

Inicialmente, Eisenstadt precisa mostrar o que define o moderno. Nesta senda, a modernidade é definida como um projeto político-cultural cujo núcleo normativo é dado pela ideia do individualismo (aspecto político) e da reflexividade (aspecto cultural). Em confronto com o período anterior, a segunda era axial é marcada pela ideia de imanência, e a ordem social é concebida como um processo contínuo de construção e reconstrução de identidades políticas e sociais. Desta forma, a ordem política ocupa um lugar central na ordem moderna e é marcada pela existência de movimentos sociais que se propõem a orientar continuamente a direção da vida social. Também a construção coletiva de identidades sociais suprime a inserção dos indivíduos em papéis definidos pela hierarquia social, e a noção de indivíduo é aberta para a reelaboração permanente. Ocorre que, longe de apenas difundir-se de forma homogênea, supondo a transição uniforme de uma ordem tradicional 
para uma ordem moderna (como supunham as teorias da modernização), Eisenstadt entende que este programa cultural (que surge na Europa Central) conhece substantivas variações tanto na sua gênese quanto no seu processo de expansão. Colocando em outros termos, podemos dizer que sua expansão quantitativa vem sempre acompanhada pela sua constante transformação qualitativa.

Já na sua origem, a própria Europa conheceu centros diversos de constituição do moderno, seja em países como França e Inglaterra, ou mesmo países de desenvolvimento tardio, como Itália e Alemanha. Além deste pluralismo inicial, nos seus momentos posteriores a Europa experimentou e oscilou entre diversos modelos políticos de condução do projeto moderno, que vão do comunismo e do nacional-socialismo, passando pelo fundamentalismo, até chegar ao Constitucionalismo de Bem-Estar Social.

Se mesmo no cenário europeu não reina nenhuma unidade, da mesma maneira, o processo de colonização das Américas (primeira onda de expansão da modernidade) também significa a concretização de uma ordem moderna diferenciada, tanto em relação à América do Norte quanto à América Latina que, longe de serem apenas "fragmentos" da Europa, constituem, na visão do autor, "civilizações" com caráter próprio, ou seja, que não apenas adotam passivamente, mas que remodelam seletivamente o projeto político-cultural da modernidade (desenvolvendo versões originais), dependendo da configuração e dos interesses de suas elites. Na sua versão anglo-americana, derivada da Reforma Protestante, grupos periféricos autônomos de seitas religiosas secularizam o princípio da igualdade e na sua versão hispânica, derivada da Contra Reforma Católica, são os atores do centro (Estado e Igreja), fundamentados no princípio da hierarquia, que moldam a civilização. Mas, até este momento, essa primeira onda de expansão e reinterpretação do projeto moderno concentra-se nos marcos do Ocidente. Uma segunda onda de expansão do projeto cultural da modernidade (cujas raízes também estão vinculadas ao imperialismo e ao colonialismo) se desdobra com sua adoção e remodelação em culturas axiais não ocidentais, em especial após a Segunda Guerra Mundial e ao lento processo de descolonização que a ele se seguiu. Neste processo devem ser colocados, como casos exemplares, o desenvolvimento de modernidades autônomas no mundo islâmico, na Índia, na China e mesmo no contexto de uma civilização não axial, caso do Japão, ao qual Eisenstadt dedicou-se com particular esmero (2010). 
No esquema de Eisenstadt, o projeto político-cultural da modernidade representa o polo da generalidade ou unicidade, enquanto os atores sociais são os fatores que determinam o polo da particularidade ou multiplicidade, quer dizer, da diversificação seletiva das diferentes versões de modernidade. Entre o geral e o particular, o fato é que a preocupação eisenstadtiana em distanciar-se das teorias da modernização (cujo núcleo explicativo comporta a tese da diferenciação institucional) leva-o a minimizar o papel das instituições em seu projeto teórico, ficando elas relegadas a variáveis condicionantes. No entanto, com o falecimento do autor, em 2010, as contribuições e limites de seu legado terão que ser enfrentados pelos membros mais jovens do círculo weberiano.

A continuidade do projeto de uma sociologia da modernidade diversificada, iniciada por Eisenstadt, tem no nome de Thomas Schwinn, que desde 2008 é sucessor de Schluchter na cátedra de teoria sociológica do Instituto de Sociologia da Universidade de Heidelberg, seu principal representante. Visando dar prosseguimento a esta empreitada, a estratégia escolhida pelo pesquisador consiste em confrontar os pressupostos da teoria das modernidades múltiplas com programas de pesquisa concorrentes. Neste trajeto, os elementos estruturais da sociologia weberiana voltam ao centro das atenções.

Se o ponto de partida da tese das modernidades múltiplas de Eisenstadt era a sociologia da religião de Max Weber, Schwinn toma como ponto de partida a teoria weberiana das esferas de valor e ordens de vida. Neste trajeto, ele não só acompanha a tentativa de situar o pensamento weberiano para além da dicotomia ação/estrutura (Schwinn, 1993a), como também busca reconstruir analiticamente o esquema sociológico das esferas de valor que Weber apresenta em sua Consideração Intermediária (Weber, 1989). Neste caso, a tese central do trabalho de Schwinn (2001) consiste na identificação de uma versão weberiana de diferenciação social que, ao contrário da visão funcionalista e sistêmica, não recorre a um conceito maior de "sociedade" e, ao mesmo tempo, prescinde da tese de que são necessidades funcionais as responsáveis pela diferenciação das instituições. Recorrendo aos textos de Weber, as esferas de valor da religião, da economia, da política, da erótica, da arte, da ciência e também do direito são decompostas em um complexo esquema que contempla três aspectos centrais que, segundo a sistematização que já conhecemos de Schluchter, incluem a dimensão da cultura, da ordem e da ação. Na dimensão cultural, cada esfera rege-se em tor- 
no de uma referência valorativa específica (Eigengesetzlichkeit) que difere segundo seu potencial de agregação social. No plano micro, cada esfera de ação implica padrões distintos de orientação da ação.

Na rápida esquematização que posso oferecer aqui ${ }^{9}$, cabe destacar que, no estudo de Schwinn (2001), na esfera econômica, a referência de sentido é dada pela busca do ganho, institucionalizado na esfera do mercado e orientado por um sentido de ação guiado por interesses (Zweckrationalität). A ordem jurídica e a ordem política são passíveis de institucionalização na forma de organizações estáveis que monopolizam instâncias de coação; não obstante, suas referências valorativas (poder e previsibilidade da ação) precisam estar ancoradas em mecanismo de legitimação, o que significa que as formas de orientação da ação agregam à dimensão dos interesses elementos de ordem normativa (Wertrationalität). No campo das esferas culturais, a arte e a erótica envolvem referências valorativas não racionais (o belo e o prazer) e que, por isso, possuem fraco poder de agregação social, desembocando em formas estilizadas de conduta (arte) ou em relações efêmeras (erótica) com linhas de ação fortemente ancoradas no aspecto afetivo. Já a diferenciação entre ciência e religião desemboca em uma esfera que monopoliza o saber racional (ciência), organizada em instituições altamente competitivas, cujos atores orientam-se por interesses e valores e outra (religião) que se especializa na esfera irracional da salvação em comunidades religiosas (Igrejas ou Seitas) orientando-se fundamentalmente por padrões valorativos e afetivos. Usando como plataforma esta leitura, Schwinn busca situar a perspectiva das modernidades múltiplas em relação às suas perspectivas concorrentes, em especial aquelas que acentuam os aspectos "homogêneos" (estruturais) da arena global, como as teorias da globalização, dos sistemas-mundo (Wallerstein) e, de forma privilegiada, da sociedade mundial (Luhmann); ou mesmo heterogêneos (culturais) do contexto mundial, como as diversas tendências da hibridização. Ambos os aspectos são reavaliados tendo como parâmetro a teoria weberiana das esferas de valor, tal como esboçada acima.

Vejamos, pois, como Schwinn (2006a) utiliza este esquema no tocante à primeira das dimensões envolvidas: seu componente estrutural. Como responder ao desafio proposto por Luhmann, para quem as distintas regiões geográfico-culturais são apenas diferenciações internas de uma variedade de sistemas sociais que operam segundo seus códigos internos? Em termos globais, a proposta luhmaniana é criticada por re- 
importar os déficits teóricos das velhas teorias da modernização, que incluem: 1) a dualidade tradicional $x$ moderno, 2 ) uma visão homogênea das esferas institucionais, 3 ) a linearidade dos processos de transição e 4) pressupostos normativos teleológicos e otimistas. A teoria luhmaniana peca por simplesmente apresentar em outro nível o pressuposto da convergência, segundo o qual os processos de modernização são, ao fim e ao cabo, cópias que são transladadas de um contexto para outro. A visão autopoiética é criticada ainda por simplesmente ignorar o papel da cultura que fica reduzida a subproduto do próprio sistema. Mas, o que tem Schwinn a oferecer como visão alternativa a esta abordagem?

A resposta esboçada por Schwinn (2006a) consiste em propor outra compreensão da natureza e do papel do que em Luhmann são chamados sistemas sociais e que, na proposta weberiana, vem apresentado como esferas de valor e ordens de vida. Trata-se de aplicar as premissas que Eisenstadt empregou na reformulação da sociologia weberiana das religiões também para sua teoria institucional, tal como descrita na Consideração Intermediária. Seguindo esta estratégia, Schwinn entende que, na ordem social da segunda era axial, marcada pelo princípio da imanência e da reflexividade, a religião perde seu lugar central (novo padrão evolutivo ou princípio da unicidade). O deslocamento da esfera transcendente do centro para a periferia da ordem social abre caminho para um novo arranjo institucional. Weber descreveu como, diante deste desafio, emergiu, no contexto europeu-moderno, uma constelação institucional própria. No entanto, a constelação esboçada por Weber não é a única possível, pois, diante dos desafios colocados pela nova realidade moderna, várias outras respostas também são possíveis (princípio da diferenciação).

Naturalmente, tal procedimento não implica afirmar que Weber tenha proposto um modelo uniforme de descrição de esferas sociais, cuja lógica expandir-se-ia automaticamente em qualquer tempo e lugar, como pressupunham as teorias da modernização. O que se enfatiza é que na sociologia de Weber encontramos apenas a descrição de uma constelação historicamente contingente de esferas sociais (Europa) que não é fadada a repetir-se: o grau de diferenciação e de autonomia de cada uma delas obedece a padrões variados e pode alterar-se ao longo do tempo e em diferentes sociedades. Da mesma forma, Weber contemplou as relações de "afinidade eletiva" (protestantismo, capitalismo, burocracia, direito formal-racional caminham em direção comum), 
bem como de "tensão e conflito" (religião e mundo) entre as esferas sociais, elementos que também não obedecem a modelos predeterminados. Partindo dessas bases, Schwinn entende que a expansão globalizada das esferas institucionais não obedece a um modelo de difusão homogênea, pois a constelação (diferenciação, autonomia, relações de afinidade e conflito) em que as esferas sociais podem ser encontradas, em contextos regionais específicos, também é múltipla.

Tal compreensão da proposta de Weber abre caminho para descrever arranjos institucionais diferentes daquele contemplado por ele, seja em relação à sua lógica interna (em que cada esfera é isoladamente considerada), seja em relação à sua lógica externa (que trata das múltiplas relações entre as ordens sociais). No caso da "lógica interna", cabe perguntar, por exemplo, até que ponto variações nos padrões de institucionalização das ordens sociais podem ser detectadas, permitindo-nos falar de diferentes modelos de capitalismo ou de democracia, por exemplo. Em outros termos, mesmo isoladamente considerada, uma esfera de valor ou ordem social determinada não possui, necessariamente, o mesmo padrão de organização interna. Já do ponto de vista externo, o modo de combinação entre estas ordens sociais também pode resultar em conglomerados diversos. Schwinn cita como exemplos casos em que uma das esferas busca sobrepor-se às demais: o predomínio da lógica do mercado (neoliberalismo), a extensão ilimitada do político (totalitarismo), bem como tentativas de retomar o predomínio do religioso sobre o tecido social ou de alçar visões de mundo seculares, sejam sexuais (erotismo), estéticas ou científicas, ao posto de visões abrangentes de mundo (fundamentalismo).

Em síntese, o argumento consiste em afirmar que o conteúdo interno, bem como as relações de autonomia, de afinidade e tensão que as ordens sociais institucionais manifestam ao longo de sua variação temporal ou espacial, é um fator contingente que, de modo nenhum, supõe a reprodução automática daquele identificado e descrito por Weber no seu horizonte histórico e sociocultural. Nessa medida, pode-se dizer que, enquanto em Eisenstadt, é o projeto político-cultural da modernidade que se encarna de forma diversificada em cada civilização, no caso de Schwinn, é uma constelação determinada de ordens sociais que pode variar. De um lado, a multiplicidade da modernidade é descrita como um processo de concretização multifacetado de uma ordem normativa. No outro caso, como um processo de concretização multifacetado de uma constelação institucional. 
Mas não é apenas na dimensão sincrônica que é preciso romper com a isonomia luhmaniana. Outro fator a ser contemplado diz respeito ao potencial de expansão e difusão das ordens sociais modernas, elemento que nos remete à dimensão diacrônica. Neste caso, o procedimento de Schwinn consiste em identificar qual o potencial que cada uma das esferas sociais possui enquanto mecanismo gerador de "processos de societarização globais" [globale Vergesellschaftungsprozesse]. Com base na descrição de sua lógica interna [Eigengesetzlichkeit], Schwinn elabora um ranking mediante o qual a qualidade e o alcance de difusão global das ordens sociais podem ser identificados e observados. O principal critério a definir este potencial é o seu grau de racionalidade formal, pois ela pode ser mensurada por instrumentos de desempenho e de concorrência. Neste modelo, é o mercado que possui o maior potencial de difusão global, tendo a racionalidade do lucro como critério ordenador e a competição como mecanismo de sanção (Produto Interno Bruto - PIB e outros instrumentos matemáticos permitem, também, comparações rápidas). Critérios de concorrência também seriam claros na esfera da ciência (número de publicações etc.), da tecnologia (registro de patentes etc.) e da educação (quantidade de prêmios nobéis etc.). Em um segundo nível operam as instituições políticas e jurídicas que, a despeito de semelhanças formais, estão impregnadas por elementos valorativos que divergem culturalmente. A discussão sobre a validade universal dos direitos humanos é o exemplo nominado por ele. Aqui critérios de desempenho são muito mais fluidos. Finalmente, abaixo da escala, encontram-se a esfera religiosa, a dimensão da arte e produção de bens culturais, contexto em que mecanismos de sanção e ao mesmo tempo critérios comparativos são bastante fracos.

Voltemo-nos agora para outra dimensão de análise, pois de fato, a pesquisa de Schwinn não se limita apenas à análise das estruturas. Central para suas intenções é determinar quais são as relações entre o nível estrutural e o nível cultural (Schwinn, 2006b e 2009). Indagando-se sobre o modo como as principais teorias sociológicas contemporâneas entendem a relação entre "estrutura" e "cultura", ele identifica três modelos de análise. Segundo os pressupostos da linha da "convergência" (cujos modelos são Fukuyama, Ritzer ou mesmo a teoria luhmaniana), os processos de mundialização engendram padrões culturais globalmente compartilhados. Na direção oposta, na linha da "divergência" (Huntington), afirma-se que o quadro global é formado de blocos de culturas ou civilizações que se isolam ou mesmo entram em conflito umas com as outras. Finalmente, uma terceira variante, denominada 
da "hibridização" (Robertson) ressalta os processos de influência recíproca que, nos diversos países e regiões do planeta, emergem entre influências culturais globais e padrões culturais locais.

No seu balanço crítico, Schwinn entende que, nos dois primeiros moldes, a ideia de cultura é hipostasiada e essencializada, seja porque uma determinada cultura simplesmente substitui a outra (visão sistêmica), seja porque cada bloco cultural permanece impermeável a qualquer influência externa (visão de Huntington). Neste sentido, ele prefere dialogar criticamente com a alternativa da hibridização. Mas, o que parece problemático ao autor, nesta vertente, é a ideia de que diferentes sociedades nacionais estariam a engendrar uma síntese de sua própria cultura nacional com a cultural global em uma espécie de "terceira cultura" (híbrida), sem esclarecer como coletividades sociais poderiam integrar indivíduos que dispõem de referências normativas divergentes. Para Schwinn, estudos focados em fenômenos como migração, por exemplo, negam esta possibilidade. Como escapar dessas diferentes formas de reducionismo?

Para solucionar este dilema, Schwinn (2006b) retoma os pressupostos de sua plataforma teórica que, como já sabemos, adota a teoria weberiana das esferas de valor. Neste caso, elas são aplicadas para entender fenômenos de tipo cultural. Também aqui a pergunta central diz respeito a 1) capacidade de difusão e de 2) hibridização, contida em diferentes dimensões da vida cultural. Isto o leva a distinguir três dimensões culturais com suas correspondentes lógicas ou racionalidades. A primeira, chamada de estética, diz respeito aos produtos culturais de massa, como tipos de comida, vestuário, música etc. Elementos culturais deste tipo são facilmente generalizáveis, pois possuem elementos cognitivos e normativos fracos. Em termos weberianos, eles obedecem a uma racionalidade estético-expressiva de tipo subjetivo, quer dizer, obedecem a juízos estéticos de gosto. Eles não deixam de carregar consigo componentes de suas identidades nacionais de origem, mas além de estandardizados para consumo, eles não implicam a capacidade de impregnar por inteiro uma cultura alheia, que os recebem segundo suas próprias referências normativas: as culturas alvos destes produtos incorporam tais elementos a partir de seus próprios critérios internos, sem ser afetadas em seus padrões estruturais básicos. É este fator que explica por que bens de consumo são os elementos culturais mais "globalizáveis", ou seja, com o maior poder de difusão e ao mesmo tempo "hibridização" em escala global. 
Já os elementos normativos de uma cultura obedecem à lógica da racionalidade ética: valores não podem ser racionalmente fundamentados, mas são passíveis de crítica racional. Por esta razão, elementos culturais normativos precisam ser institucionalizados e incorporados pelos indivíduos mediante processos de socialização. Além disso, a capacidade de difusão global de padrões culturais normativos não é intrínseca e é fortemente dependente da ação impulsionadora de fatores institucionais (fóruns globais, ONU, organizações internacionais etc.). Por outro lado, a hibridização de elementos normativos, como a noção de direitos humanos ou valores democráticos, é muito mais fraca, pois tais caracteres precisam ser culturalmente interpretados e traduzidos nos moldes dos padrões regionais/locais.

Finalmente, na dimensão cognitiva, o grau de racionalidade dos juízos torna-se ainda mais forte. Critérios de aceitação de resultados científicos são altamente padronizáveis e, na mesma medida, passíveis de rápida transnacionalização. No entanto, o modo de articulação destes padrões globais com os saberes locais (hibridização) pode variar desde sua coexistência, substituição do padrão local pela visão externa ou mesmo incorporação local de estilos de pensamento. Não obstante, quanto mais autônoma é a lógica da esfera científica, tanto mais ela tende a absorver o conteúdo dos saberes locais segundo sua própria lógica formal. No esquema de Schwinn, o potencial de globalização e de hibridização de padrões culturais é uma variável dependente do tipo de racionalidade formal e material de cada esfera cultural envolvida. Em regra, quanto mais "formal" a racionalidade da dimensão cultural a ser analisada, tanto maior é seu potencial de expansão global e de hibridização local.

Embora a pesquisa de Schwinn seja um trabalho ainda em andamento, fica claro como sua proposta possui uma ambição bem menor do que o trabalho de Eisenstadt. Enquanto este último se propunha a identificar diferentes civilizações modernas que consistem em cristalizações diferenciadas do projeto cultural da modernidade, Schwinn reduz sua análise à apreciação do potencial de difusão e absorção das instituições e padrões culturais modernos que, bem diferente de Eisenstadt, não redundam em formações socioculturais diferenciadas. Na acepção de Schwinn, a ideia de "modernidade múltipla" fica reduzida a uma "metadefinição" sem um conteúdo específico. Mesmos os casos empíricos utilizados por ele como ilustrações são mais localizados, como as diferenças institucionais entre o capitalismo no Japão e na Alemanha ou 
mesmo a pergunta sobre o lugar da Turquia no contexto cultural europeu. Na sua análise, a dimensão estrutural e a dimensão cultural ocupam o foco da análise, mas ambas são pensadas de forma paralela e a relação entre os dois elementos fica indeterminada. Por outro lado, o elemento fundante da sociologia weberiana (seu foco na orientação da ação) praticamente desaparece e parece não ocupar maior lugar na teorização do autor.

\section{WEBER COMO PARADIGMA?}

Após a descrição do estado da arte do projeto de constituição de um parâmetro paradigmático/programa de pesquisa orientado segundo Weber (tanto no plano metateórico quanto no plano teórico-empírico), a pergunta a ser feita é sobre a validade, contribuições e limites deste esforço ainda em andamento. Visando oferecer um primeiro balanço deste empreendimento, pretendo seguir duas direções. Em primeiro lugar, um programa de pesquisa com base em Weber precisa confirmar-se no seu confronto com as propostas concorrentes. Neste caso, o que precisa ser feito é avaliar em que medida o conteúdo do "neoweberianismo" permite avanços na agenda das discussões com as quais ele mesmo resolveu travar confronto. A relação que aqui se estabelece é entre esta leitura de Weber e os problemas de pesquisa contemporâneos. Outra linha de avaliação volta-se para o próprio ponto de partida da discussão e se pergunta o que significa, de fato, atualizar conceitos weberianos quando nos voltamos para o autor em si mesmo: aqui, a relação que se trava é entre o weberianismo lido no presente e suas fontes. Quais os aspectos da obra de Weber são reativados e o que isto implica na imagem de Weber que emerge de sua reutilização? Nesta parte final, tomarei a avaliação "prospectiva" para apontar alguns elementos de validade que podem ser extraídos da atualização de Weber. Em segundo momento, eles serão colocados em confronto com a linha "retrospectiva" de avaliação para diagnosticar também questões e problemas que tal proposta engendra. Em ambos os casos busco localizar, de modo positivo, os desafios que o projeto de atualização da obra de Weber ainda precisa enfrentar.

Para uma ciência multiparadigmática como a Sociologia, torna-se difícil achar um eixo unanimemente aceito que articule as posições e os debates existentes. No campo da teoria sociológica stricto sensu, desacordos à parte, o problema micro-macro tem possibilitado um critério a partir do qual as diversas tendências podem, ao menos, reconhecer 
suas posições. Particularmente forte no mundo da sociologia de corte anglo-saxão (penso aqui em Giddens, Archer e Baskhar, por exemplo), tal discussão também invade o campo da sociologia praticada na Alemanha, onde, em termos globais, luhmanianos, habermasianos e partidários da escolha racional, entre outros, disputam o terreno. Ao retomar os fundamentos metodológicos da sociologia de Weber, menos por sua perspectiva exegética e mais pela roupagem terminológica hoje em uso, teóricos como Schluchter e Albert permitem que a posição weberiana transite do mero campo da história das ideias para o campo da discussão teórica em si mesma. Isto abriu o caminho para que Weber pudesse ser transformado em fonte de orientação capaz de fornecer tanto um ponto de partida para a discussão, como também instrumentos conceituais e até posições substantivas em relação ao problema da emergência (transição do micro ao macro), da redução (ação do plano macro sobre o micro) e mesmo da orientação da ação (no plano micro-micro).

Dentre as muitas possibilidades que assim ficam abertas, cito apenas um exemplo. Entendo que, mais do que um precursor da discussão, a organização da sociologia weberiana em múltiplos planos (MehrEbenen Modell) - que compreendem a lógica da situação, a lógica da escolha e a lógica da agregação - permite que o tema da relação macro-micro avance para além da dificuldade já apontada por Archer em relação a Giddens e à ideia da dualidade da estrutura: o tratamento simultâneo dos dois níveis leva ou à redução do plano micro ao plano macro (redução deflacionária) ou à redução contrária (redução inflacionária). Mais do que uma temporalização sequencial de ambos os problemas, a disjunção de cada um destes níveis em suas características, propriedades e efeitos permite um tratamento teórico-analítico específico para cada um deles. Passemos agora ao plano substantivo da teoria da modernidade.

Max Weber foi, entre os clássicos da Sociologia, o autor que organizou sua teoria da modernidade não tanto por um aporte exclusivamente diacrônico, tendo como base a transição do tradicional para o moderno (como é o caso de Durkheim com a dicotomia solidariedade mecânica / orgânica e de Marx com sua sucessão de modos de produção), mas integrando a ela um procedimento comparativo segundo o qual a definição do moderno emerge não como uma forma civilizacional exclusiva de racionalismo, mas como uma variante contingente, ao lado de outras possibilidades históricas (China e Índia, em particular). Em 
tempos de globalização e de crítica ao eurocentrismo, tal elemento não torna sua análise imune de críticas, mas surpreendentemente atual. Ao desenvolver suas análises do mundo moderno na plataforma comparativa, autores como Eisenstadt e Schwinn estão ancorados em uma das mais profícuas potencialidades da análise de Weber. Mas, longe de apenas repetir o diagnóstico weberiano, tais autores também estão convencidos de que o comparativismo weberiano precisa ser complementado e enriquecido, permitindo-nos avançar do problema da "gênese" da modernidade para seus desdobramentos posteriores. Neste quesito, o léxico categorial weberiano contribui com elementos oriundos de sua sociologia cultural (elemento ressaltado por Eisenstadt) ou mesmo de sua sociologia estrutural (elemento ressaltado por Schwinn), permitindo que ele possa ser colocado ao lado das discussões que buscam entender fenômenos globais sem perder de vista a difícil relação entre elementos gerais e particulares e entre elementos estruturais ou simbólicos.

Mas, se até aqui, o esforço de velhos e novos weberianos mostra que proposições oriundas dos escritos de Weber são passíveis de uma atualização produtiva, o que significa falar, exatamente, de um "paradigma"? Em que medida uma proposta como esta não acaba regredindo na pura exegese, ou, por outro lado, não corre o risco de enrijecer o pensamento de Weber em algum tipo de "weberianismo" ortodoxo? O que significa orientar-se pelas premissas de Weber e, ao mesmo tempo, atualizá-lo, corrigi-lo e superá-lo? Também aqui a agenda é vasta e gostaria de destacar apenas dois pontos.

Sob a perspectiva teórica, se uma sociologia de tipo weberiano caracteriza-se pela sua modelização em três níveis, em que do plano básico da ação social passa-se ao plano emergente da ordem social e deste para o plano mais vasto da cultura (conforme modelo fixado por Schluchter), resta que as propostas aqui resenhadas exibem divergências que dificultam agrupá-las em único marco paradigmático. Para Albert, por exemplo, Weber sequer pode ser situado no plano do individualismo metodológico e sua posição reside em uma tendência não reducionista que o autor ora define como holismo de tipo fraco, ora como síntese (pouco explicada) entre coletivismo e individualismo. Por que Albert, partindo de seu próprio esquema, simplesmente não classificou Weber no campo de um individualismo metodológico (não atomista) é uma pergunta difícil de responder. Da mesma forma, se examinarmos as posições de Eisenstadt e Schwinn (que trabalham no campo empíri- 
co-comparativo), veremos que o primeiro opera com a variável dependente ação e independente cultura, esvaziando o nível estrutural. Já em Schwinn, estrutura e cultura ocupam o papel analítico, mas a relação entre os dois pontos não é esclarecida e - parece - corre paralela, sem pontos de ligação. Quanto aos atores, ao final, eles não ocupam, praticamente, nenhum papel. Se, por um lado, tais variações mostram que o programa não é rígido (permitindo explorar de forma variada cada um dos níveis de análise), ocorre que se exibe pouca unidade se o que estamos a procurar é um paradigma ou mesmo um programa de pesquisa formalmente articulado.

Deixando o campo dos modelos teóricos formais e aterrissando no campo empírico da explanação de fenômenos sociais de longo alcance, de fato, chama a atenção como a ideia de múltiplas modernidades (seja ela concebida em termos substantivos/Eisenstadt ou metacognitivos/Schwinn) está fortemente desconectada daquele que me parece ser o eixo da teoria weberiana da gênese e formato da modernidade: sua teoria da racionalização. O que em Weber eram diferentes modelos socioculturais de racionalismo (adaptação, fuga, aceitação ou dominação do mundo) construídos levando em consideração os tipos de racionalidade teórica ou prática simplesmente desaparece em Eisenstadt, reduzindo-se a uma variante culturalista concebida como projeto. Somente em Schwinn os rastros do conflito entre racionalidade material e formal ainda se deixam apresentar, timidamente, em sua análise do potencial de globalização e hibridização de estruturas e padrões culturais. Uma teoria da modernidade que leve em conta novos desdobramentos da racionalidade (como a racionalidade contingente dos meios, contida na tecnicidade da modernidade) poderia ser aqui uma pista promissora nesta direção ${ }^{10}$.

Ao final, cabe perguntar se não perde a conexão com o núcleo do pensamento weberiano um paradigma no qual a prioridade analítica da ação social perde espaço para a tentativa de situar forçadamente Weber em alguma forma de equilíbrio entre a dimensão micro/macro. O autor possui evidentes contribuições para pensar os múltiplos lados da questão, mas é exatamente no nível das formas de orientação da ação (ou lógica da situação) que se situa o ponto nevrálgico e forte de sua teoria: “o que ele sustenta é que o ponto de partida da análise sociológica só pode ser dado pela ação de indivíduos e que ela é 'individualista' quanto ao método" (Cohn, 1991:26, ênfases no original). Da mesma forma poderíamos nos perguntar se não abandona o eixo da reflexão 
de Weber uma leitura das múltiplas modernidades onde o conteúdo da teoria civilizatória do autor não é mais a racionalidade prática da dominação do mundo, mas apenas um esquema comparativista de tipo formal, ora reduzido a uma variante cultural, ora estrutural. Em que medida podem-se chamar estas orientações de paradigma, quiçá mesmo de um programa de pesquisa orientado segundo Max Weber?

\section{CONSIDERAÇÕES FINAIS}

A recepção do pensamento de Weber na própria Alemanha comporta sucessivas ondas de fluxo e refluxo. Após uma relativa disseminação inicial, ela foi interrompida durante a Segunda Guerra Mundial, transladando-se seu centro de importância para os Estados Unidos. No pós-guerra, o predomínio quase exclusivo da Escola de Frankfurt e de sua versão de teoria crítica relegou Weber ao combatido campo do sempre indeterminado "positivismo". No entanto, já na metade dos anos 1970, o campo dos especialistas em Weber, liderado por figuras importantes da academia alemã como Wolfgang Schluchter, Rainer Lepsius, Wolfgang Mommsen e, em associação com os mesmos, Shmuel Eisenstadt e outros, reorganiza suas forças e lidera um longo projeto que, além da republicação de suas obras (Max Weber Gesamtausgabe) propôs um novo marco hermenêutico de intelecção da obra weberiana em torno de sua sociologia da religião e do tema dos processos de racionalização. Repatriado e ancorado em nova disposição de seus escritos, Weber volta a ser exportado mundo afora.

Partindo dos marcos estabelecidos por esta primeira geração, podemos identificar, atualmente, uma segunda onda de pesquisadores, no momento em busca de ascensão na estrutura acadêmica e intelectual alemã, que vem se esmerando na tentativa de desenvolver um programa de pesquisas orientado segundo as premissas da sociologia weberiana. Menos centrada na exegese e no objetivo de fixar um marco hermenêutico, a preocupação destes pesquisadores é retomar os impulsos deixados por Weber em função de problemas colocados na agenda teórica e empírica da sociologia contemporânea. Partindo de certo cânon interpretativo, tais pesquisadores enfrentam o desafio de torná-lo instrumentalmente produtivo como recurso nas disputas acadêmicas. Neste processo, podemos identificar quatro estratégias metodológicas: 1) Em primeiro lugar, temas, enfoques, autores e conceitos do horizonte teórico continental ou mesmo anglo-saxão contemporâneo são empregados como plataforma para retomar e reatualizar problemas e 
elementos do pensamento de Weber. Paradoxal é que o ponto de partida da discussão acabe não sendo a plataforma de Weber em si mesma, mas as premissas sugeridas pelo chamado "novo movimento teórico" em sua ânsia por integrar, em perfeita simetria, as "duas sociologias" nas quais se reparte a comunidade sociológica. Não seria o caso de indagar por que o novo movimento teórico prescreve a Weber o lugar do individualismo metodológico e questionar este enquadramento, se não mesmo a própria dicotomia?; 2) este é um ponto que mereceria maior desdobramento mas, por ora, quero chamar a atenção para o fato de que, ainda assim, este processo de adaptação do (neo)weberianismo ao marco do novo movimento teórico não tem como meta, obviamente, o abandono da tradição e, bem ao contrário, visa tornar o pensamento de Weber uma alternativa viável nas discussões em curso: a absorção externa opera como meio para o fim da retomada interna; 3 ) neste processo, mais do que elementos isolados, o pensamento weberiano é concebido como "conjunto", pensado ora como paradigma em sentido forte (Kuhn) ou fraco (Merton) ou apenas como Programa de Pesquisa (Lakatos). Nem observações empíricas limitadas nem conceitos isolados, Weber é aqui apresentado enquanto instrumento abrangente de compreensão e explicação de problemas teóricos e empíricos; 4) a partir deste enfoque global, tanto elementos "formais" quanto "substantivos" são retomados, consistindo, basicamente, dos eixos ação e ordem social (macro-micro) e, em termos substantivos, na determinação do papel das instituições modernas (mercado, Estado, Ciência, Direito etc.) e suas representações simbólico-normativas (o projeto cultural da modernidade no contexto global).

Tendo em vista tratar-se de um processo em andamento, tanto uma descrição dos trabalhos realizados, bem como uma avaliação dos resultados alcançados, só podem ser provisórias. Mais do que julgamentos definitivos, talvez seja interessante prestar atenção às questões de fundo que tal projeto levanta. Pode realmente a sociologia weberiana deslocar-se do campo da "história" para o campo da "teoria" como paradigma concorrente na verdadeira selva de propostas teóricas que rondam a sociologia contemporânea? Em suma: um "programa de pesquisa de orientação weberiana" (para retomar aqui outra formulação) é realmente possível (e necessário)? De nosso ponto de vista, entendemos que sim. Mas, mesmo sendo positiva a resposta, nova série de questões ainda ficam à espera de resposta: qual a imagem de Weber que lhe segue como resultado? Até onde é possível acompanhá-lo, de que forma é necessário complementá-lo, em que pontos ele precisa ser 
superado? Em que medida um paradigma weberiano se aproxima e se distancia do Weber clássico apresentando-se como mais ou menos ortodoxo ou heterodoxo? Fazer perguntas, em si mesmo, já significa muita coisa. Se Weber ainda nos consegue mobilizar para repensar questões teóricas e, principalmente, lançar um olhar sobre o mundo social atual, talvez não saibamos exatamente se já temos diante de nós um paradigma (ou um programa de pesquisa) para nos guiar ou não. O fato é que, praticamente 150 anos depois, Max Weber ainda consegue dialogar produtivamente conosco e parece que tem algo importante a nos dizer sobre este mundo do século XXI.

(Recebido para publicação em julho de 2013) (Aprovado para publicação em outubro de 2013) 


\section{Carlos Eduardo Sell}

\section{NOTAS}

1. Dentre as visões alternativas: Kalberg (1994) e Hennis (1987).

2. O que nos leva, por sinal, ao encontro de diversos outros comentadores, como Guenther Roth (1968) e Gabriel Cohn (2003), no Brasil, por exemplo. Agradeço ao parecerista anônimo que, acertadamente, chamou-me a atenção para este ponto. Em tempo, também, para agradecer às preciosas indicações que foram sugeridas por ambos os avaliadores de Dados e que, sempre que possível, procurei incorporar, ainda que tenha consciência de que alguns temas tenham que ser aprofundados ulteriormente.

3. Para uma avaliação crítica deste debate, consultar Vandenberghe (2010).

4. Tal publicação, cujo original inglês foi publicado em 1996, está agora disponível em português (Schluchter, 2012).

5. A proposta de interpretação de Schluchter privilegia claramente o confronto com o pensamento habermasiano. Um cotejo entre a dimensão racional da ação weberiana e o projeto de concepção reflexiva da agência (conforme Giddens) ainda está por ser realizado.

6. Individualismo/Atomismo/Subjetivismo versus Holismo/Estruturalismo/Sistemismo/Coletivismo, notará o leitor, são termos intercambiáveis na discussão que, até o presente momento, ainda não encontraram detalhamentos analíticos mais cuidadosos. Na falta de um consenso técnico-linguístico (aliás, incomum nas Ciências Sociais), adoto como referência padrão o primeiro de cada um dos termos de cada conjunto.

7. Em 2005, por exemplo, os coordenadores do Grupo de Teoria Sociológica da Associação Nacional de Pós-Graduação e Pesquisa em Ciências Sociais (Anpocs) já organizavam um GT sobre "As modernidades múltiplas". Cabe assinalar, ainda, que há uma tradução em português facilmente disponível (Eisenstadt, 2001), ampliando a difusão desta vertente no Brasil. A tradução de um capítulo da obra de Wolfgang Knöbl (2006) também é um momento importante neste processo de recepção. A coletânea de textos de Sérgio Costa, José Maurício Domingues, Wolfgang Knöbl e Josué Silva também oferece um bom balanço do debate (em especial a Introdução e o capítulo de Wilfried Spohn), mas, até o momento, não foi traduzida para o português (The Plurality of Modernity: Decentring Sociology. Rainer Hammp, München, 2006).

8. O próprio autor fornece uma concisa e instrutiva reconstrução de sua trajetória teórica em Eisenstadt (2006:9-38).

9. Ideal seria apontar, com vagar, os detalhes da riquíssima reflexão weberiana das esferas de valor e ordens de vida, tal como exposta na Consideração Intermediária. Dada a restrição de espaço, remeto o leitor à excelente sistematização de Habermas (2012) e aos importantes detalhamentos de Cohn (2003) e Waizbort (1995). Meu ponto de vista sobre o assunto é apresentado em Sell (2013).

10. Esforço que, em conjunto com Brüseke (2012), resulta de sua parte na busca pela reflexão sobre a "modernidade técnica" (Brüseke, 2002) e, de minha parte, na identificação de fundamentos weberianos para uma teoria da racionalidade técnica. Esta não é nem a racionalidade de "fins" nem de "valores", mas racionalidade de "meios" (Sell, 2011). 


\section{REFERÊNCIAS BIBLIOGRÁFICAS}

ALBERT, Gert. (2005), “Moderater metodologischer Holismus. Eine weberianische Interpretation des Makro-Mikro-Makro Modells". Kölner Zeitschrift für Soziologie und Sozialpsychologie, vol. 57, pp. 387-413.

(2009), "Weber-Paradigma”, in G. Kneer e M. Schroer (orgs.), Handbuch Soziologischen Theorien. Wiesbaden, Verlag für Sozialwissenschaften, pp. 517-554.

(2010), “Handlungstheorien mittlerer oder universaler Reichweite? Zu einer latenten methodologischen Kontroverse", in G. Albert e S. Sigmund (orgs.), Soziologische Theorie Kontrovers. Kölner Zeitschrift für Soziologie und Sozialpsychologie, 50, pp. 526-561.

. (2011), "Moderater Holismus: emergentische Methodologie einer dritten Soziologie", in J. Greve e A. Schnabel (orgs.), Emergenz: Zur Analyse und Erklärung komplexer Strukturen. Berlin, Suhrkamp, pp. 252-285.

ALBERT, Gert et al. (2003), Das Weber-Paradigma. Tübingen, Mohr Siebeck.

ALBERT, Gert et al. (2006), Aspekte des Weber-Paradigmas. Festchrift für Wolfgang Schluchter. Wiesbaden, Verlag für Sozialwissenschaften.

ALEXANDER, Jeffrey. (1987), “O Novo Movimento Teórico”. Revista Brasileira de Ciências Sociais, vol. 2, no 4, pp. 5-28.

(1992), "The Fragility of Progress. An Interpretation of the Turn to Meaning in Eisenstdt's Later Work". Acta Sociologica, vol. 35, no 2, pp. 85-94.

ALEXANDER, Jeffrey e COLOMY, Paul. (1985), “Toward Neo-Functionalism: Eisenstadt's Change Theory and Symbolic Interaction". Sociological Theory, vol. 3, no 2, pp.11-23.

BIENFAIT, Agathe (org.). (2011), Religions Verstehen: Zur Aktualität von Max Webers Religionssoziologie. Wiesbaden, VS Verlag.

BRÜSEKE, Franz Josef. (2002), “A Modernidade Técnica”. Revista Brasileira de Ciências Sociais, vol. 17, no 49 , pp. 135-144.

BRÜSEKE, Franz Josef (org.). (2012), Teoria Social e Técnica. Porto Alegre, EDPUCRS.

COLEMAN, James S. (1990), Foundations of Social Theory. Harvard, Harvard University Press.

COHN, Gabriel. (1991), "Introdução", in G. Cohn e F. Fernandes (orgs.), WEBER. São Paulo, Ática, pp. 7-35 (Coleção Grandes Cientistas Sociais).

. (2003), Crítica e Resignação: Max Weber e a Teoria Social. São Paulo, M. Fontes.

COSTA, Sérgio et al. (2006), The Plurality of Modernity: Decentring Sociology. Rainer Hammp, München.

DOMINGUES, José Maurício. (2013), Modernidade Global e Civilização Contemporânea: Para uma Renovação da Teoria Crítica. Belo Horizonte, Editora UFMG.

EISENSTADT, Shmuel. (1963), The Political Systems of Empires. New York, Free Press. (1966), Modernization: Protest and Change. Englewood Cliffs, Prentice Hall. 


\section{Carlos Eduardo Sell}

. (1968), Max Weber on Charisma and Institution Building. Chicago/London, University of Chicago Press.

(1978), Revolution and the Transformation of Societes. New York, The Free Press.

. (1982), "The Axial Age: The Emergence of Transcendental Visions and the Rise of the Clerics". Archives Européennes de Sociologie, vol. 23, pp. 299-314.

. (1986), The Originis and Diversity of Axial Civilizations. New York, Albany.

(2001), “Modernidades Múltiplas". Sociologia, no 35, pp. 139-163.

(2006), “Die Dimensionen komparativer Analyse und die Erforschung sozialer Dinamik. Von der vergleichenden Politikwissenschaft zum Zivilisationsvergleich". Theorie und Moderne: Soziologische Essays. Wiesbaden, pp. 9-38.

(2010), “Modernidade Japonesa: A Primeira Modernidade Múltipla Não Ocidental". Dados, vol. 53, no 1, pp. 11-54.

ESSER, Hartmut. (1993), Soziologie: Allgemeine Grundlagen. Frankfurt/Main/New York, Campus Verlag.

GREVE, Jens. (2006), “Max Weber und Emergenz. Ein Programm eines nichtreduktionistischen Individualismus?", in G. Albert et al. (orgs.), Aspekte des Weber-Paradigmas. Festchrift für Wolfgang Schluchter. Wiesbaden, Verlag für Sozialwissenschaften.

HABERMAS, Jürgen. (1981), Max Weber Theorie der Rationalisierung. Theorie des kommunikativen Handelns: Handlungsrationalität und gesellschaftliche Rationalisierung. Suhrkamp, Frankfurt am Main, pp. 225-368.

(2012), Conteúdo Sistemático da Zwischenbetrachtung Teoria do Agir Comunicativo. São Paulo, Martins Fontes, pp. 411-425.

HENNIS, Wilhelm. (1987), Max Webers Fragestellung. Studien zur Biographie des Werkes. Tübingen, Mohr Siebeck.

JASPERS, Karl. (1949), Vom Ursprung und Ziel der Geschichte. München \& Zürich, Artemis Verlag.

JOAS, Hans e KNÖBL, Wolfgang. (2004), Sozialtheorie: Zwanzig einführende Vorlesung. Die Erneuerung des Parsonianismus und der Modernisierungstheorie. Suhrkamp, Frankfurt am Main, pp. 430-473.

KALBERG, Stephen. (1994), Max Weber's Comparative Historical Sociology. Chicago, Chicago University Press.

KNÖBL, Wolfgang. (2006), “Max Weber, as Múltiplas Modernidades e a Reorientação da Teoria Sociológica". Dados, vol. 49, no 3, pp. 483-509.

LEPSIUS, M. Rainer. (1990), Ideen, Interessen und Institutionen. Opladen, Westdeutschland Verlag.

(2003), “Eigenart und Potenzial des Weber-Paradigmas", in G. Albert et al. (orgs.), Das Weber-Paradigma. Tübingen, Mohr Siebeck, pp. 32-41.

McClELLAND, David C. (1961), The Achieving Society. Princeton, N.J., Van Nostrand.

PIERUCCI, Antônio Flávio. (2003), O Desencantamento do Mundo: Todos os Passos do Conceito em Max Weber. São Paulo, Editora 34. 
POHLMANN, Markus. (2006), “Weber, Sombart und die neue Kapitalismustheorie”, in G. Albert et al. (orgs.), Aspekte des Weber-Paradigmas. Festchrift für Wolfgang Schluchter. Wiesbaden, Verlag für Sozialwissenschaften, pp. 185-192.

PREYER, Gerhard. (2011), Zur Aktualität von Shmuel N. Einsenstadt: Einleitung in sein Werk. Wiesbaden, VS Verlag.

ROTH, Guenther. (1968), "Introduction", in M. Weber. Economy and Society. New York, Bedminster, vol.1, pp. xxvii-civ.

SCHLUCHTER, Wolfgang. (1981), The Rise of Western Rationalism: Max Webers Developmental History. Berkeley, Berkeley University Press.

(2000), "Handlungs und Rationalität nach Max Weber". Individualismus, Verantwortungsethik und Vielfalt. Göttingen, Velbrück Wissenschaft, pp. 86-103.

(2005), Handlung, Ordnung und Kultur: Studiem zum einem Forschunsprogramm in Anschluss an Max Weber. Tübingen, Mohr Siebeck.

(2009), “Die Soziologische Grundbegriffe: Max Webers Grundlegung einer verstehenden Soziologie". Die Entzauberung der Welt. Tübingen, Mohr Siebeck, pp. 111-136.

. (2012), "Epílogo: Ação, Ordem e Cultura", in Paradoxos da Modernidade: Cultura e Conduta na Teoria de Max Weber. São Paulo, Editora da Unesp, pp. 325-330.

SCHWINN, Thomas. (1993a), Jenseits von Subjektivismus und Objektivismus: Max Weber, Alfrend Schütz und Talcott Parsons. Berlin, Duncker \& Humblot.

(1993b), “Max Webers Konzeption des Mikro-Makro Problems”. Kölner Zeitschrift für Soziologie und Sozialpsychologie, vol. 45, pp. 220-237.

(2001), Differenzierung ohne Gesellschaft. Umstellung eines soziologischen Konzepts. Weilerswist, Velbrück.

. (2004), “Von der historischen Entstehung zur aktuellen Ausbreitung der Moderne. Max Weber Soziologie im 21". Berliner Journal für Soziologie, vol. 14, pp. 527-544.

. (2006a), “Die Vielfalt und die Einheit der Moderne. Perspektiven und Probleme eines Forschungsprograms", in Die Vielfalt und die Einheit der Moderne: Kultur-und strukturvergleichenden Analysen. Wiesbanden, VS Verlag, pp. 7-34.

(2006b), "Konvergenz, Divergenz oder Hybridiserung? Voraussetzungen und Erscheinungsformen von Weltkultur". Kölner Zeitschrift für Soziologie und Sozialpsychologie, vol. 58, no 2, pp. 201-232.

(2009), “Multiple Modernities: Konkurrierenden Thesen und offene Fragen. Ein Literaturbericht in konstruktiver Absicht". Zeitschrift für Soziologie, vol. 38, no 6, pp. 454-476.

SCHWINN, Thomas, KRONEBERG, Clemens e GREVE, Jens (orgs.). (2011), Soziale Differenzierung: Handlungstheoretische Zugänge in der Diskussion. Wiesbaden, VS Verlag.

SIGMUND, Steffen e ALBERT, Gert. (2008), Soziale Konstellation und historische Perspektive: Festrift für M. Rainer Lepsius. Wiesbanden, Verlag für Sozialwissenschaften.

SELL, Carlos Eduardo. (2011), “Máquinas Petrificadas: Max Weber e a Sociologia da Técnica". Scientia Studia, vol. 9, no 3, pp. 563-583. 


\section{Carlos Eduardo Sell}

(2013), Max Weber e a Racionalização da Vida. Petrópolis, RJ, Vozes.

STACHURA, Mateusz et al. (orgs.). (2009), Der Sinn der Institutionen: Mehr-Ebenen-und Mehr-Seiten Analyse. Wiesbanden, Verlag für Sozialwissenschaften.

TENBRUCK, Friedrich. (1975), “Das Werks Max Weber”. Kölner Zeitschrift für Soziologie und Sozialpsychologie, vol. 27, no 4, pp. 663-702.

VANDENBERGHE, Frédéric. (2010), Teoria Social Realista: Um Diálogo Franco-Britânico. Belo Horizonte/Rio de Janeiro, Ed. UFMG/Iuperj.

WAIZBORT, Leopoldo. (1995), "Introdução”, in M. Weber, Os Fundamentos Racionais e Sociológicos da Música. São Paulo, EdUSP, pp. 9-19.

WEBER, Alfred. (1997), Kulturgeschichte als Kultursoziologie. Marburg, Metropolis Verlag (Alfred-Weber Gesamtausgabe 1).

WEBER, Max. (1989), “Zwischenbetrachtung. Die Wirtschaftsethik der Weltreligionen. Konfuzianismus und Puritanismus (Schriften 1915-1920)", in H. Schmidt-Glinzer e P. Kolonko (orgs.), Tübingen: Mohr Siebeck. pp. 479-522 (Max Weber Gesamtausgabe MWG I/19).

\section{ABSTRACT}

Weber in the $21^{\text {st }}$ century: Challenges and Dilemmas of a Weberian Paradigm

After decades of intensive work in the exegesis of Weber's work, research on this author in Germany led to the characterization of his work on the theme of rationalization. Based on this assumption, a more recent generation of researchers has attempted to formulate a proposal for updating Weberian theory, contrasting it with the principal problems in contemporary sociological analysis. What are the characteristics of this "Weberian paradigm" and how should it be evaluated in light of the contemporary theoretical agenda? Based on these questions, the article examines how the Weberian research program fits into the dispute over the link between agency (micro level) and structure (macro level) in social theory. The second topic of analysis deals with the theory of modernity and evaluates the attempt by its interpreters to unfold Weberian studies from the genesis to the diversification of modernity (multiple modernities).

Key words: Max Weber; methodological holism; methodological individualism; multiple modernities; Weberian paradigm 


\section{RÉSUMÉ}

\section{Weber au XXIe Siècle: Enjeux et Dilemmes d'un Paradigme Wéberien}

La recherche effectuée en Allemagne sur Weber, après des décennies d'un travail intense d'exégèse sur son œuvre, a abouti à caractériser celle-ci par le thème de la rationalisation. À partir de là, une nouvelle génération de chercheurs essaie, plus récemment, $\mathrm{d}^{\prime}$ actualiser cette théorie en la confrontant aux principales questions soulevées par l'analyse sociologique contemporaine. Quels sont les traits du "paradigme wéberien" et comment peut-il être évalué dans le contexte des théories contemporaines? Depuis cette base, on examine la façon dont le programme de recherche wéberien s'insère dans la discussion sur l'articulation entre agences (plan micro) et structures (macro) en théorie sociale. Le second point analyse la théorie de la modernité et evalue la tentative de ses interprètes de déplacer les recherches wéberiennes du plan de la genèse vers le plan de la diversification de la modernité (modernités multiples).

Mots-clés: Max Weber; holisme méthodologique; individualisme méthodologique; modernités multiples; paradigme wéberien

\section{RESUMEN}

Weber en el Siglo XXI: Desafíos y Dilemas de un Paradigma Weberiano

Después de décadas de intensivo trabajo de exegesis de la obra de Weber, una amplia investigación realizada en Alemania sobre este autor condujo a la caracterización de su obra en torno al tema de la racionalización. A partir de este presupuesto, una nueva generación de investigadores viene intentando formular una propuesta de actualización de la teoría weberiana, por medio de su confrontación con los principales problemas de análisis de la sociología contemporánea. ¿Cuáles son las características del "paradigma weberiano" y cómo evaluarlo en términos de agenda teórica contemporánea? Con base en estas cuestiones, se examina, en primer lugar, cómo el programa de investigación weberiano se inserta en la disputa alrededor de la articulación entre agencia (plano micro) y estructura (macro) en la teoría social. El segundo eje de análisis trata la teoría de la modernidad y evalúa el intento de sus intérpretes de desplegar las investigaciones weberianas del plano de la génesis al plano de la diversificación de la modernidad (modernidades múltiples).

Palabras clave: Max Weber; holismo metodológico; individualismo metodológico; modernidades múltiples; paradigma weberiano 
